\title{
Review Article \\ Recent Advances in Genetic Technique of Microbial Report Cells and Their Applications in Cell Arrays
}

\author{
Do Hyun Kim, ${ }^{1}$ Moon Il Kim, ${ }^{1}$ and Hyun Gyu Park ${ }^{2}$ \\ ${ }^{1}$ Department of Bionano Technology, Gachon University, Gyeonggi 461-701, Republic of Korea \\ ${ }^{2}$ Department of Chemical and Biomolecular Engineering (BK21+ Program), Korea Advanced Institute of Science and \\ Technology (KAIST), Daejeon 305-701, Republic of Korea
}

Correspondence should be addressed to Moon Il Kim; moonil@gachon.ac.kr and Hyun Gyu Park; hgpark@kaist.ac.kr

Received 23 April 2015; Accepted 26 August 2015

Academic Editor: Yun-Peng Chao

Copyright (C) 2015 Do Hyun Kim et al. This is an open access article distributed under the Creative Commons Attribution License, which permits unrestricted use, distribution, and reproduction in any medium, provided the original work is properly cited.

\begin{abstract}
Microbial cell arrays have attracted consistent attention for their ability to provide unique global data on target analytes at low cost, their capacity for readily detectable and robust cell growth in diverse environments, their high degree of convenience, and their capacity for multiplexing via incorporation of molecularly tailored reporter cells. To highlight recent progress in the field of microbial cell arrays, this review discusses research on genetic engineering of reporter cells, technologies for patterning live cells on solid surfaces, cellular immobilization in different polymers, and studies on their application in environmental monitoring, disease diagnostics, and other related fields. On the basis of these results, we discuss current challenges and future prospects for novel microbial cell arrays, which show promise for use as potent tools for unraveling complex biological processes.
\end{abstract}

\section{Introduction}

Biosensors, which have been widely utilized for the detection of target molecules, are increasingly important, owing to their broad applications in biotechnology and related fields, including disease diagnostics, environmental monitoring, drug discovery, and food processing [1]. Biosensor is operated mainly based on the specificity of biologically active molecules, including nucleic acids, enzymes, antibodies and antigens, receptors, and cells, and thus these substances are fundamental for the specific recognition of target molecules.

Among biosensors, cell-based or whole-cell biosensors have garnered particular interest because they can provide unique data on the global activities of test samples, such as their toxicity, genotoxicity, or bioavailability, from a direct assay on live cells [2]. The use of live cells also allows for reagent-free, nondestructive real-time monitoring of the biological effects as they develop, with no need for the pre- or posttreatment steps that are generally required for conventional chemistry-based analytical methods. Therefore, the use of whole cells as sensing entities can conveniently provide a diverse array of data on integrated biological effects that cannot be achieved using other biosensors, although the relative insufficiency of their specificity is inevitable, based on the nature of living systems.

Previous cell-based biosensors typically used a single type cells, with a single function, to analyze a single sample; however, recent approaches have focused on the development of arrays comprised of multiple cells on a mapped solid surface that are subsequently exposed to mixtures containing multicomponent analytes, which can provide multiplexed output signals corresponding to the amount of each target in the sample mixture [3]. Compared to singleplex cellbased biosensors, cell arrays enable simultaneous detection of multiple samples with multiple output signals that can be used to rapidly analyze large numbers of samples. Due to the increased need for multiplex, high-throughput analysis capability, cell array techniques have recently garnered significant attention [4].

Diverse types of cell arrays have been reported. In particular, human cells have been extensively employed to develop miniaturized cell-based assay platforms, which include microfluidic and microarray biochips to mimic human metabolism [5-9]. These biochips have been extensively used 


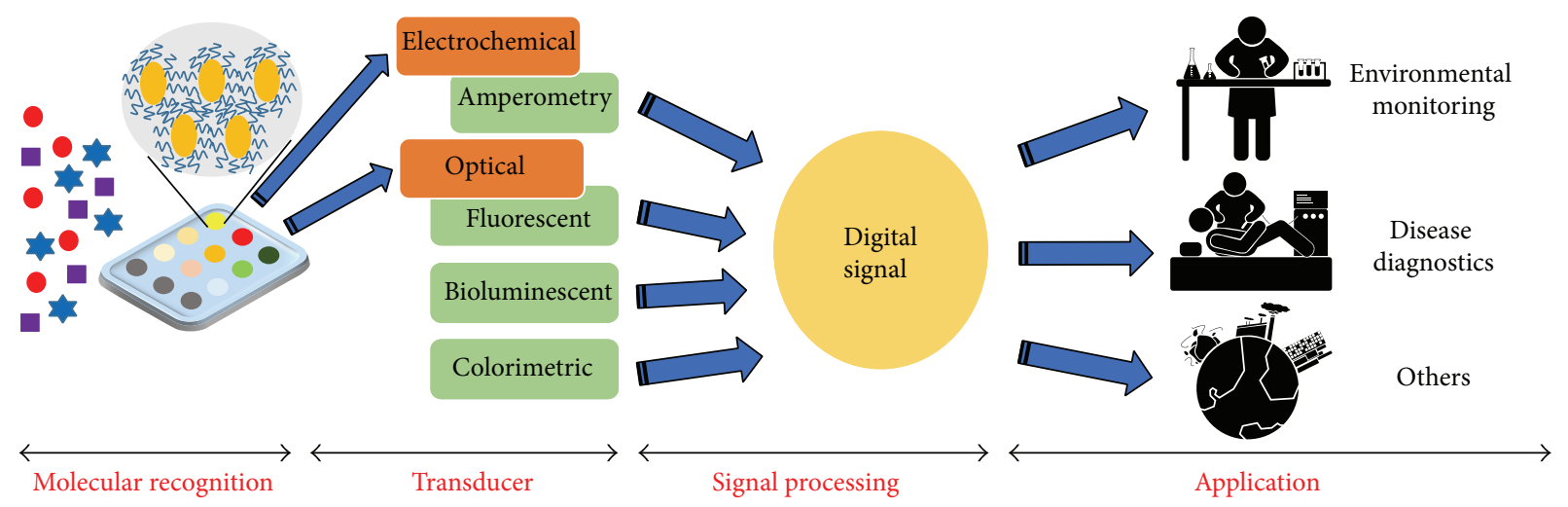

FIGURE 1: A schematic representation of a microbial cell array.

in drug discovery to evaluate toxicity and other metabolic activities during adsorption, distribution, metabolism, and elimination of drug candidates in the human body [5]. Other eukaryotic cells, including yeast, have also been examined in applications for gene function analysis, microphysiometry, and therapeutic agent identification based on array platforms prepared using diverse microfabrication strategies such as photolithography, inkjet printing, or microcontact printing [10-17]. Due to the critical need for high-throughput methods for investigating the bioactivity of eukaryotic cells, cell arrays based on eukaryotic cells have come into widespread use.

In contrast, arrays using prokaryotic cells have numerous differentiated benefits [18]. It is easy to grow and to maintain the viability of prokaryotic cells at low cost, large and homogeneous populations are easily obtainable, they are robust to a variety of physical and chemical environments, and they show low susceptibility to biological contamination. Furthermore, prokaryotic cells are amenable to physical or chemical manipulation, particularly those required for patterning in an array format. Perhaps their most important characteristic, based on recent developments in genetic engineering technology, is that prokaryotic cells can be molecularly engineered to respond in a dose-dependent manner, to yield readily quantifiable optical (colorimetric, fluorescent, or luminescent) or electrochemical signals to predetermined targets such as chemicals, biomolecules, or biological effects [3]. This is generally achieved by the fusion of a sensing element, a selective promoter along with its regulatory elements, to a suitable molecular reporter system. Moreover, advances in genetic engineering also allow the expression of two independent reporter systems in a single microorganism, facilitating multiplex analysis and particular logic operations of microbial cell arrays [19-21]. These genetically engineered sensor cells are patterned on a solid surface, incorporated into a single hardware platform, and simultaneously exposed to a sample, for applications such as environmental monitoring, disease diagnostics, and others (Figure 1). Due to the significance and widespread applicability of this state-of-the-art technology, it has garnered increasing public attention, and a reasonable research direction must be set to widely expand its utilization for both laboratory and field use.
In this paper, we review recent advances in microbial cell arrays. Recent research into genetic engineering of reporter cells, technologies for patterning live cells on solid surfaces, and their immobilization in different polymers are extensively discussed, along with studies of related applications. We present the current challenges and future prospects for novel microbial cell arrays, which can be used as potent tools for unraveling complex biological processes.

\section{Genetic Engineering of Microbial Reporter Cells}

Although unmodified bacteria have been used as biosensors, based on changes in natural bioluminescence as cells grow, genetic engineering of microbial cells is extensively employed to rationally produce dose-dependent signals to predetermined environmental stimuli [22, 23]. Typical engineering methods include fusion of a reporter gene system to promoters from selected stress-response regions, resulting in specific cell growth and easily measurable signals that are proportional to the quantity of target analytes, including chemicals, nutrients, or heavy metals. To date, fluorescence- and luminescence-based signals have typically been produced in microbial cell arrays by the activity of corresponding reporter genes that express fluorescent protein and bacterial luciferase (lux), respectively $[24,25]$. In recent years, several attempts have been made to improve the performance of reporter cells, such as further engineering of regulatory regions, splitting of the lux operon, increasing cellular permeability, or shuffling of gene elements [26-31].

Recently, another class of genetic engineering, based on construction of mutant bacteria with auxotrophic characteristics, has garnered attention, owing to its capacity to specifically and sensitively detect diverse types of metabolites present in the metabolic pathways of the microbial cells on the array $[32,33]$. Several different strategies, such as transposon or N-methyl-N' ${ }^{\prime}$-nitro-N-nitrosoguanidine- (NTG-) induced mutagenesis and chromosomal gene deletion based on linear cassettes, have been employed to prepare auxotrophic bacteria $[34,35]$. Bioluminescence-producing firefly luciferase or fluorescent protein reporter genes have also been used to produce corresponding optical responses that are proportional to 
the concentrations of target analytes. These cell arrays were proven to enable rapid $(<4 \mathrm{~h})$ and simultaneous analysis of multiple targets from complex biological fluids $[33,36]$.

As described above, the signals generated by the arrays have primarily been produced by proteins or by the activity of an enzyme expressed using a reporter gene system. Depending on the type of reporter gene, the signals emitted have been detected optically or electrochemically. Additional signaling methods based on commercially available Live/Dead staining or surface plasmon resonance analysis have also been reported, for diversification of cell array detection mechanisms $[37,38]$.

\section{Patterning Microbial Cells on Solid Surfaces}

In addition to cell arrays patterned in the wells of premade microtiter plates, target microbial cells can be patterned on a solid surface, to maximize the number of cell spots per unit area while enabling the activity of each spot to be distinguished from that of its neighbors, without crosscontamination. Diverse microfabrication strategies, such as photolithography, soft lithography, and noncontact printing, have been employed to prepare patterned cell arrays on numerous materials such as silicon, glass, various polymers, and gold [38-44].

Photography-based processes have been widely applied to prepare patterns of immobilized bacterial cells. Typically, a water-soluble photoresist polymer is employed for the fabrication of a three-dimensional matrix on the desired region by simple exposure to UV light, resulting in accommodation of both target cells and culture medium in the matrix. Using this strategy, silicon chips consisting of microfluidic channels, microchambers, valves, and additional structures have successfully been prepared for toxicity monitoring, based on generation of Escherichia coli microspots on a planar array [40].

Microcontact printing, one of the most conventionally used soft lithography methods to prepare patterns with a chemical moiety, has been employed to create cellular patterns on both planar and nonplanar surfaces, by delivering anchor molecules using a polydimethylsiloxane (PDMS) stamp [45]. Using this stamp, self-assembled monolayers, which can adsorb to patterned gold surfaces, form covalent bonds with a protein that guides a cell to the pattern. Using this strategy, high-resolution printing of massive arrays of various microorganisms, such as Lactobacillus plantarum, E. coli, Candida albicans, and fungal spores of Aspergillus fumigatus, has been reported on porous aluminum oxide [46]. Another bacterial array, based on a combination of self-assembled polyelectrolyte multilayers and micromolded poly(ethylene glycol)-poly(lactide) diblock copolymers to promote target cell adhesion, has also been reported [47].

As an example of noncontact printing, piezoelectric inkjet printers have been used to prepare high-density live cell arrays for screening antimicrobial activity [48]. Flickinger et al. reported the formulation of reactive microbial inks and the use of piezo tips to spot $E$. coli at designated positions [49]. A noncontact robotic printer was also employed to prepare $E$. coli arrays with several nanoliter-volume spots on chemically modified glass [50].

\section{Maintenance of Cell Viability}

For practical application of microbial cell arrays, cells on the array should maintain their viability and be able to be stored for sufficiently long periods of time. Thus, development of efficient solid-phase arrays by appropriate immobilization of cells has garnered consistent attention, particularly in industry. Various polymers, such as agar, agarose, alginate, collagen, latex, polyacrylamide, polyethylene glycol diacrylate, and carrageenan, as well as freeze/vacuum drying, have been reported to immobilize cells while retaining sufficient viability $[25,33,43,49,51-56]$. In particular, further addition of components such as glycerol or trehalose was shown to effectively provide extracellular or intracellular protection and thus to enhance the long-term survival rate $[50,57]$. Vacuum drying of As(III) reporter bacteria in the presence of $34 \%$ trehalose and $1.5 \%$ polyvinylpyrrolidone resulted in very effective preservation of initial activity during up to 12 weeks of storage at $4^{\circ} \mathrm{C}[58]$. An innovative strategy based on the formation of bacterial spores was also reported for longterm (up to 2 years) preservation of sensing cells at room temperature [59].

\section{Applications of Microbial Cell Arrays}

Based on their abovementioned characteristics, microbial cell arrays have been used in diverse applications for monitoring the global effects of test samples, as shown briefly in Table 1 . In this section, we describe recent studies of the application of microbial cell arrays, categorized by environmental monitoring, disease diagnostics, and others.

5.1. Environmental Monitoring. Although the envisaged applications of microbial cell array are numerous, they have primary been applied in the environmental field. Microbial cells have been elaborately modified to produce both qualitative and quantitative outputs in response to single or multiple kinds of environmental stimuli and applied to construct cell arrays to analyze multiple test samples. Due to their capacity to show the unique responses of live cells, microbial cell arrays can serve as a potent analytical route to replace the conventional yet laborious methods currently in use.

Several microbial cell arrays have been developed for assaying heavy metals, which are regarded as major toxic elements. Biran et al. reported a microbial cell array that employs a genetically engineered E. coli strain that contains the lac $Z$ reporter gene, which can express $\beta$-galactosidase, fused to a the promoter of a heavy metal-responsive gene. A plasmid carrying the gene coding for the enhanced cyan fluorescent protein was subsequently introduced into this sensing strain to produce concomitant optical signals in proportion to the quantity of the target heavy metal, mercury. Levels as low as $100 \mathrm{nM} \mathrm{Hg}^{2+}$ could be detected after only $1 \mathrm{~h}$ of incubation [60]. Arsenic and cadmium were also simultaneously quantified via a multichannel bioluminescent 
TABLE 1: Recent applications of microbial cell arrays.

\begin{tabular}{|c|c|c|c|c|}
\hline Application field & Target & Microorganism & Detectable output & References \\
\hline $\begin{array}{l}\text { Environmental } \\
\text { monitoring }\end{array}$ & Mercury & Recombinant Escherichia coli & Fluorescence & {$[60]$} \\
\hline $\begin{array}{l}\text { Environmental } \\
\text { monitoring }\end{array}$ & $\begin{array}{c}\text { Cadmium and arsenic } \\
\text { III }\end{array}$ & Recombinant E. coli & Bioluminescence & {$[61]$} \\
\hline $\begin{array}{l}\text { Environmental } \\
\text { monitoring }\end{array}$ & $\begin{array}{l}\text { Silver and titanium } \\
\text { oxide nanoparticles }\end{array}$ & Recombinant E. coli & Gene expression profile & {$[62]$} \\
\hline $\begin{array}{l}\text { Environmental } \\
\text { monitoring }\end{array}$ & Endocrine disruptors & Recombinant yeast and E. coli & Bioluminescence & {$[53]$} \\
\hline $\begin{array}{l}\text { Environmental } \\
\text { monitoring }\end{array}$ & Cell-damaging stress & Recombinant E. coli & Bioluminescence & {$[63]$} \\
\hline $\begin{array}{l}\text { Environmental } \\
\text { monitoring }\end{array}$ & Naphthenic acid & Recombinant E. coli & Fluorescence & {$[64]$} \\
\hline $\begin{array}{l}\text { Environmental } \\
\text { monitoring }\end{array}$ & $\begin{array}{l}\text { Paraquat, mitomycin } \\
\mathrm{C} \text {, and salicylic acid }\end{array}$ & Recombinant E. coli & Bioluminescence & {$[25]$} \\
\hline Disease diagnostics & 16 amino acids & Recombinant E. coli auxotroph & Bioluminescence & {$[33]$} \\
\hline Disease diagnostics & Homocysteine & Recombinant E. coli auxotroph & Bioluminescence & {$[65]$} \\
\hline Disease diagnostics & Galactose & Recombinant E. coli auxotroph & Bioluminescence & {$[66]$} \\
\hline Disease diagnostics & $\begin{array}{l}\text { Phenylalanine, } \\
\text { methionine, and } \\
\text { leucine }\end{array}$ & Recombinant $E$. coli auxotroph & Fluorescence & {$[36]$} \\
\hline $\begin{array}{l}\text { Carbohydrates } \\
\text { detection }\end{array}$ & $\begin{array}{l}\text { Mono- and } \\
\text { disaccharides }\end{array}$ & Recombinant E. coli & $\mathrm{O}_{2}$ reduction & {$[55]$} \\
\hline $\begin{array}{l}\text { Gene expression } \\
\text { analysis }\end{array}$ & $\begin{array}{l}\text { Growth of E. coli } \\
\text { colonies }\end{array}$ & Recombinant E. coli & Gene expression profile & {$[67]$} \\
\hline Screening antibiotics & Antibiotic activity & Staphylococcus aureus & Bioluminescence & {$[68]$} \\
\hline $\begin{array}{l}\text { Screening } \\
\text { pharmaceuticals }\end{array}$ & 420 pharmaceuticals & Recombinant E. coli & Bioluminescence & {$[69]$} \\
\hline
\end{tabular}

E. coli array system, although cross-reactivity was observed when the two metals were mixed [61].

Other environmental pollutants have also been monitored using microbial cell arrays. Gou et al. utilized a green fluorescent protein-fused recombinant $E$. coli array to assess the mechanistic toxicity of silver and titanium oxide nanoparticles by measuring real-time gene expression profiles [62]. A portable biosensor device, based on engineered yeast and bacterial cells fused to a reporter gene expressing luciferase, was reported to be able to detect several endocrine disruptors, including androgens and estrogens [53]. Ahn et al. reported an E. coli array consisting of optically coded functional microbeads containing both bioluminescent reporter bacterial cells and fluorescent microspheres for broad-range toxicity monitoring [63]. A bacterial cell array using recombinant E. coli in 384-well plates was also employed in a genomewide investigation of the toxic mechanisms of naphthenic acids, chemicals that pose serious environmental hazards and which are present in effluents from petrochemical processing [64]. Three different chemicals that cause either superoxide damage (paraquat), DNA damage (mitomycin C), or protein/membrane damage (salicylic acid) were also successfully detected within $2 \mathrm{~h}$, using a bacterial cell array based on bioluminescent E. coli [25].
5.2. Disease Diagnostics. Recently, cell-based assays employing fast-growing auxotrophic bacteria supplemented with bioluminescent or fluorescent reporter genes have been shown to rapidly, conveniently, and simultaneously detect multiple target molecules relevant to human diseases. In contrast to conventional diagnostic methods, which often require numerous experimental steps or complicated and expensive instrumentation, bacterial auxotroph-based arrays show rapid, specific, and sensitive cell growth in direct response to the concentration of the corresponding molecules. This method can also be extended to evaluate or monitor nutritional conditions, as the metabolic pathways of microbial cells contain many relevant metabolites.

Several cell-based approaches to diagnosis of human diseases have been reported. A multiplexed amino acid array for simultaneously quantifying 16 different amino acids based on the rapid and specific growth of amino acid-auxotrophic E. coli was reported [33]. Using this array, multiple amino acids in biological fluids were quantitatively determined within $4 \mathrm{~h}$, simply by measuring bioluminescent signals from immobilized cells, without any pre- or posttreatment. Using this system, two different kinds of metabolic diseases of newborn babies, phenylketonuria and homocystinuria, were successfully diagnosed by measuring luminescence values 
from phenylalanine and methionine auxotrophs incubated with an eluted mixture from clinical blood paper specimens. Similarly, homocysteine, an important marker for cardiovascular disease and other syndromes such as Alzheimer's and Parkinson's disease, neural tube defects, pregnancy complications, and osteoporosis, was quantified by employing another bioluminescent $E$. coli array, which showed high specificity, sensitivity, and excellent levels of precision and reproducibility [65]. Galactosemia, a major metabolic disorder of newborns, was also successfully diagnosed by employing galT-knockout E. coli [66]. Furthermore, simultaneous quantification of multiple amino acids in a single biological sample was reported and applied in the multiplexed diagnosis of three key metabolic diseases of newborn babies [36]. The assay utilized three E. coli auxotrophs that grow only in the presence of the corresponding target amino acids and contain three different fluorescent reporter plasmids that produce distinguishable fluorescence signals (red, green, and cyan) in concert with cell growth. The three auxotrophs were mixed and immobilized in the same well of a 96-well plate and consequently yielded three different fluorescence signals that corresponded to the reporter plasmids. The clinical utility of this assay system was demonstrated by employing it to identify metabolic diseases of newborns through the quantification of phenylalanine, methionine, and leucine in clinically derived dried blood specimens.

5.3. Others. Based on their unique advantages, the applications for microbial cell arrays are currently being expanded. Held et al. reported a bacterial cell array with an automated flow-injection system for the selective and simultaneous determination of various mono- and disaccharides [55]. The selectivity of the array was achieved by combination of the metabolic responses of $E$. coli mutants lacking different transport systems for individual carbohydrates. The array enabled simultaneous detection of three major sugars, fructose, glucose, and sucrose, in test samples. A unique array of bacterial colonies has been reported for large-scale gene expression analysis [67]. In this system, recombinant E. coli clones containing plasmid-encoded copies of several thousand individually expressed sequence tags were spotted and incubated for $\sim 6 \mathrm{~h}$ to allow bacterial growth and consequent amplification of the cloned tags. For use in drug discovery, an array of Staphylococcus aureus fused with lux (luciferaseproducing) plasmids was reported for screening antibiotic activity [68]. Finally, a panel of 15 bioluminescent E. coli containing multiple bacterial reporter genes associated with oxidative stress, DNA damage, heat shock, and efflux of excess metals was arrayed to screen a library of 420 pharmaceuticals [69]. This work demonstrated that microbial cell arrays can play a significant role in drug development alongside in vitro toxicity tests.

\section{Conclusion and Future Prospects}

As described above, microbial cell arrays have been widely investigated and have garnered significant attention as a potent analytical paradigm, due to their capacity to provide unique global data for live systems. The arrays provide
TABLE 2: Representative advantages and challenges of microbial cell arrays.

\begin{tabular}{|c|c|}
\hline Advantages & Challenges \\
\hline $\begin{array}{l}\text { (1) Analysis of global } \\
\text { activities of target analyte }\end{array}$ & $\begin{array}{l}\text { (1) Limited viability and } \\
\text { biological function }\end{array}$ \\
\hline (2) Low cost & (2) Insufficient specificity \\
\hline $\begin{array}{l}\text { (3) Analysis is more } \\
\text { convenient than existing } \\
\text { technologies }\end{array}$ & $\begin{array}{l}\text { (3) Types of target analytes are } \\
\text { limited }\end{array}$ \\
\hline $\begin{array}{l}\text { (4) Robust to reaction } \\
\text { environments }\end{array}$ & $\begin{array}{l}\text { (4) Genetic stability of } \\
\text { engineered reporter cell system is } \\
\text { low }\end{array}$ \\
\hline $\begin{array}{l}\text { (5) Simultaneous detection } \\
\text { of multiple analytes }\end{array}$ & $\begin{array}{l}\text { (5) Laws limiting the use of } \\
\text { genetically modified organisms }\end{array}$ \\
\hline $\begin{array}{l}\text { (6) Real-time, in situ } \\
\text { monitoring }\end{array}$ & $\begin{array}{l}\text { (6) Slow diffusion in cell } \\
\text { membranes }\end{array}$ \\
\hline
\end{tabular}

the option, which was previously unavailable, of analyzing biological reactions via real-time monitoring of the responses of an unlimited number of genetically tailored sensor strains, which provide easily measurable, dose-dependent optical or electrical signals within a short period of time. However, several challenges that significantly hinder the widespread utilization of microbial cell arrays remain, such as their limited viability and biological function after long-term storage, insufficient specificity, limited types of target analytes, and problems in genetic engineering of sensor strains (Table 2). However, significant progress to overcome these limitations is continuously being made, as shown in some of the approaches reviewed here, and microbial cell arrays show great promise for an increasing number of applications in diverse fields such as environmental monitoring, disease diagnostics, and drug discovery.

For microbial cell arrays to be positioned as a nextgeneration analytical tool, the following technological hurdles must be overcome before the technology matures. Possibly the most urgent need for practical applications is a dramatic improvement in the maintenance of cell activity and viability over prolonged periods of time. Many different approaches have been suggested, such as appropriate immobilization of cells or addition of particular additives to reduce stress factors; however, other innovative methods to significantly extend the shelf life of arrays are required, particularly for commercialization in industry. In addition, further engineering of reporter cells for higher specificity, sensitivity, and robustness or better methodologies for incorporation of such cells into hardware platforms will also greatly contribute to the widespread utilization of this technology. When they mature, microbial cell arrays may become an efficient and practical analytical tool in diverse biotechnological fields.

In summary, this paper highlights recent progress in the field of microbial cell arrays. Although the relative insufficiency of their specificity is inevitable, based on the nature of living systems, microbial cell arrays can provide unique data on the global activity of test samples with a range of advantages that are not achievable using other analytical methods. Diverse technological advances have provided the 
tools, materials, and elaborately engineered reporter cells needed to construct highly integrated arrays. Based on the unique advantages and continued progress in this field, we believe that microbial cell arrays will lead a new wave of novel diagnostic methods in environmental monitoring, disease diagnostics, drug screening, and other related fields.

\section{Conflict of Interests}

The authors declare that there is no conflict of interests regarding the publication of this paper.

\section{Acknowledgments}

This work was supported by the Basic Science Research Program through the National Research Foundation of Korea (NRF) funded by the Ministry of Science, ICT \& Future Planning (NRF-2014R1A1A1006016) and by the Gachon University Gil Medical Center (Grant no. 2014-22). This research was also supported by Basic Science Research Program through the National Research Foundation of Korea (NRF) funded by the Ministry of Education [no. 2015R1A2A1A01005393].

\section{References}

[1] J. Kirsch, C. Siltanen, Q. Zhou, A. Revzin, and A. Simonian, "Biosensor technology: recent advances in threat agent detection and medicine," Chemical Society Reviews, vol. 42, no. 22, pp. 8733-8768, 2013.

[2] S. Melamed, T. Elad, and S. Belkin, "Microbial sensor cell arrays," Current Opinion in Biotechnology, vol. 23, no. 1, pp. 2-8, 2012.

[3] T. Elad, J. H. Lee, M. B. Gu, and S. Belkin, "Microbial cell arrays," Advances in Biochemical Engineering/Biotechnology, vol. 117, pp. 85-108, 2010.

[4] T. Elad, E. Benovich, S. Magrisso, and S. Belkin, "Toxicant identification by a luminescent bacterial bioreporter panel: application of pattern classification algorithms," Environmental Science \& Technology, vol. 42, no. 22, pp. 8486-8491, 2008.

[5] M.-Y. Lee and J. S. Dordick, "High-throughput human metabolism and toxicity analysis," Current Opinion in Biotechnology, vol. 17, no. 6, pp. 619-627, 2006.

[6] P. J. Hung, P. J. Lee, P. Sabounchi, R. Lin, and L. P. Lee, "Continuous perfusion microfluidic cell culture array for highthroughput cell-based assays," Biotechnology and Bioengineering, vol. 89, no. 1, pp. 1-8, 2005.

[7] J. Ziauddin and D. M. Sabatini, "Microarrays of cells expressing defined cDNAs," Nature, vol. 411, no. 6833, pp. 107-110, 2001.

[8] C. J. Flaim, S. Chien, and S. N. Bhatia, "An extracellular matrix microarray for probing cellular differentiation," Nature Methods, vol. 2, no. 2, pp. 119-125, 2005.

[9] M.-Y. Lee, R. A. Kumar, S. M. Sukumaran, M. G. Hogg, D. S. Clark, and J. S. Dordick, "Three-dimensional cellular microarray for high-throughput toxicology assays," Proceedings of the National Academy of Sciences of the United States of America, vol. 105, no. 1, pp. 59-63, 2008.

[10] H. M. McConnell, J. C. Owicki, J. W. Parce et al., "The cytosensor microphysiometer: biological applications of silicon technology," Science, vol. 257, no. 5078, pp. 1906-1912, 1992.
[11] A. M. Aravanis, B. D. DeBusschere, A. J. Chruscinski, K. H. Gilchrist, B. K. Kobilka, and G. T. A. Kovacs, "A genetically engineered cell-based biosensor for functional classification of agents," Biosensors \& Bioelectronics, vol. 16, no. 7-8, pp. 571-577, 2001.

[12] A. Waterworth, A. Hanby, and V. Speirs, "A novel cell array technique for high-throughput, cell-based analysis," In Vitro Cellular \& Developmental Biology-Animal, vol. 41, no. 7, pp. 185$187,2005$.

[13] O. E. Beske and S. Goldbard, "High-throughput cell analysis using multiplexed array technologies," Drug Discovery Today, vol. 7, no. 18, pp. S131-S135, 2002.

[14] T. H. Park and M. L. Shuler, "Integration of cell culture and microfabrication technology," Biotechnology Progress, vol. 19, no. 2, pp. 243-253, 2003.

[15] J. Alper, "Bioengineering-biology and the inkjets," Science, vol. 305, no. 5692, p. 1895, 2004.

[16] M. Mrksich and G. M. Whitesides, "Patterning self-assembled monolayers using microcontact printing - a new technology for biosensors," Trends in Biotechnology, vol. 13, no. 6, pp. 228-235, 1995.

[17] T. Xu, J. Jin, C. Gregory, J. J. Hickman, and T. Boland, "Inkjet printing of viable mammalian cells," Biomaterials, vol. 26, no. 1, pp. 93-99, 2005.

[18] J. R. van der Meer and S. Belkin, "Where microbiology meets microengineering: design and applications of reporter bacteria," Nature Reviews Microbiology, vol. 8, no. 7, pp. 511-522, 2010.

[19] R. Silva-Rocha and V. de Lorenzo, "Engineering multicellular logic in bacteria with metabolic wires," ACS Synthetic Biology, vol. 3, no. 4, pp. 204-209, 2014.

[20] B. Wang, R. I. Kitney, N. Joly, and M. Buck, "Engineering modular and orthogonal genetic logic gates for robust digitallike synthetic biology," Nature Communications, vol. 2, no. 1, article 508, 9 pages, 2011.

[21] B. J. Wang, M. Barahona, and M. Buck, "A modular cell-based biosensor using engineered genetic logic circuits to detect and integrate multiple environmental signals," Biosensors \& Bioelectronics, vol. 40, no. 1, pp. 368-376, 2013.

[22] A. Qureshi, A. Bulich, and D. Isenberg, "Microtox toxicity test systems-where they stand today," in Microscale Testing in Aquatic Toxicology: Advances, Techniques, and Practice, P. G. Wells, K. Lee, and C. Blaise, Eds., pp. 185-199, CRC Press, Boca Raton, Fla, USA, 1998.

[23] S. Belkin, "Microbial whole-cell sensing systems of environmental pollutants," Current Opinion in Microbiology, vol. 6, no. 3, pp. 206-212, 2003.

[24] Y. Kuang, I. Biran, and D. R. Walt, "Living bacterial cell array for genotoxin monitoring," Analytical Chemistry, vol. 76, no. 10, pp. 2902-2909, 2004.

[25] J. H. Lee, R. J. Mitchell, B. C. Kim, D. C. Cullen, and M. B. $\mathrm{Gu}$, "A cell array biosensor for environmental toxicity analysis," Biosensors \& Bioelectronics, vol. 21, no. 3, pp. 500-507, 2005.

[26] S. Yagur-Kroll, B. Bilic, and S. Belkin, "Strategies for enhancing bioluminescent bacterial sensor performance by promoter region manipulation," Microbial Biotechnology, vol. 3, no. 3, pp. 300-310, 2010.

[27] S. K. Srivastava, P. R. Lambadi, T. Ghosh, R. Pathania, and N. K. Navani, "Genetic regulation of spy gene expression in Escherichia coli in the presence of protein unfolding agent ethanol," Gene, vol. 548, no. 1, pp. 142-148, 2014. 
[28] S. Yagur-Kroll and S. Belkin, "Upgrading bioluminescent bacterial bioreporter performance by splitting the lux operon," Analytical and Bioanalytical Chemistry, vol. 400, no. 4, pp. 10711082, 2011.

[29] A. Biran, H. Ben Yoav, S. Yagur-Kroll et al., "Microbial genotoxicity bioreporters based on sulA activation," Analytical and Bioanalytical Chemistry, vol. 400, no. 9, pp. 3013-3024, 2011.

[30] S. Melamed, S. Naftaly, and S. Belkin, "Improved detection of antibiotic compounds by bacterial reporter strains achieved by manipulations of membrane permeability and efflux capacity," Applied Microbiology and Biotechnology, vol. 98, no. 5, pp. 22672277, 2014.

[31] J. Garmendia, A. De Las Heras, T. C. Galvão, and V. De Lorenzo, "Tracing explosives in soil with transcriptional regulators of Pseudomonas putida evolved for responding to nitrotoluenes," Microbial Biotechnology, vol. 1, no. 3, pp. 236-246, 2008.

[32] P. R. Burkholder, "Determination of vitamin B12 with a mutant strain of Escherichia coli," Science, vol. 114, no. 2966, pp. 459460, 1951.

[33] M. I. Kim, B. J. Yu, M.-A. Woo et al., "Multiplexed amino acid array utilizing bioluminescent Escherichia coli auxotrophs," Analytical Chemistry, vol. 82, no. 10, pp. 4072-4077, 2010.

[34] K. A. Datsenko and B. L. Wanner, “One-step inactivation of chromosomal genes in Escherichia coli K-12 using PCR products," Proceedings of the National Academy of Sciences of the United States of America, vol. 97, no. 12, pp. 6640-6645, 2000.

[35] W. S. Reznikoff, I. Y. Goryshin, and J. J. Jendrisak, "Tn5 as a molecular genetics tool," Methods in Molecular Biology, vol. 260, pp. 83-96, 2004.

[36] M. I. Kim, T. J. Park, N. S. Heo et al., "Cell-based method utilizing fluorescent Escherichia coli auxotrophs for quantification of multiple amino acids," Analytical Chemistry, vol. 86, no. 5, pp. 2489-2496, 2014.

[37] J. Heo, K. Joseph Thomas, G. Hun Seong, and R. M. Crooks, "A microfluidic bioreactor based on hydrogel-entrapped $E$. coli: cell viability, lysis, and intracellular intracellular enzyme reactions," Analytical Chemistry, vol. 75, no. 1, pp. 22-26, 2003.

[38] J.-W. Choi, K.-W. Park, D.-B. Lee, W. Lee, and W. H. Lee, "Cell immobilization using self-assembled synthetic oligopeptide and its application to biological toxicity detection using surface plasmon resonance," Biosensors \& Bioelectronics, vol. 20, no. 11, pp. 2300-2305, 2005.

[39] S. Bhattacharya, J. S. Jang, L. J. Yang, D. Akin, and R. Bashir, "BioMEMS and nanotechnology-based approaches for rapid detection of biological entities," Journal of Rapid Methods and Automation in Microbiology, vol. 15, no. 1, pp. 1-32, 2007.

[40] S. K. Yoo, J. H. Lee, S.-S. Yun, M. B. Gu, and J. H. Lee, "Fabrication of a bio-MEMS based cell-chip for toxicity monitoring," Biosensors \& Bioelectronics, vol. 22, no. 8, pp. 1586-1592, 2007.

[41] J. Fukuda, A. Khademhosseini, J. Yeh et al., "Micropatterned cell co-cultures using layer-by-layer deposition of extracellular matrix components," Biomaterials, vol. 27, no. 8, pp. 1479-1486, 2006.

[42] N. R. Thirumalapura, A. Ramachandran, R. J. Morton, and J. R. Malayer, "Bacterial cell microarrays for the detection and characterization of antibodies against surface antigens," Journal of Immunological Methods, vol. 309, no. 1-2, pp. 48-54, 2006.

[43] H. Tani, K. Maehana, and T. Kamidate, "Chip-based bioassay using bacterial sensor strains immobilized in threedimensional microfluidic network," Analytical Chemistry, vol. 76, no. 22, pp. 6693-6697, 2004.
[44] N. Q. Balaban, J. Merrin, R. Chait, L. Kowalik, and S. Leibler, "Bacterial persistence as a phenotypic switch," Science, vol. 305, no. 5690, pp. 1622-1625, 2004.

[45] L. P. Xu, L. Robert, Q. Y. Oi et al., "Microcontact printing of living bacteria arrays with cellular resolution," Nano Letters, vol. 7, no. 7, pp. 2068-2072, 2007.

[46] C. Ingham, J. Bomer, A. D. Sprenkels, A. van den Berg, W. de Vos, and J. V. H. Vlieg, "High-resolution microcontact printing and transfer of massive arrays of microorganisms on planar and compartmentalized nanoporous aluminium oxide," Lab on a Chip, vol. 10, no. 11, pp. 1410-1416, 2010.

[47] C.-H. Choi, J.-H. Lee, T.-S. Hwang et al., "Preparation of bacteria microarray using selective patterning of polyelectrolyte multilayer and poly(ethylene glycol)-poly(lactide) diblock copolymer," Macromolecular Research, vol. 18, no. 3, pp. 254-259, 2010.

[48] Q. Zheng, J. Lu, H. Chen, L. Huang, J. Cai, and Z. Xu, "Application of inkjet printing technique for biological material delivery and antimicrobial assays," Analytical Biochemistry, vol. 410, no. 2, pp. 171-176, 2011.

[49] M. C. Flickinger, J. L. Schottel, D. R. Bond, A. Aksan, and L. E. Scriven, "Painting and printing living bacteria: engineering nanoporous biocatalytic coatings to preserve microbial viability and intensify reactivity," Biotechnology Progress, vol. 23, no. 1, pp. 2-17, 2007.

[50] S. Melamed, L. Ceriotti, W. Weigel, F. Rossi, P. Colpo, and S. Belkin, "A printed nanolitre-scale bacterial sensor array," Lab on a Chip, vol. 11, no. 1, pp. 139-146, 2011.

[51] J. H. Lee, C. H. Youn, B. C. Kim, and M. B. Gu, "An oxidative stress-specific bacterial cell array chip for toxicity analysis," Biosensors \& Bioelectronics, vol. 22, no. 9-10, pp. 2223-2229, 2007.

[52] D. O. Fesenko, T. V. Nasedkina, A. V. Chudinov, D. V. Prokopenko, R. A. Yurasov, and A. S. Zasedatelev, "Alginate gel biochip for real-time monitoring of intracellular processes in bacterial and yeast cells," Molecular Biology, vol. 39, no. 1, pp. 84-89, 2005.

[53] A. Roda, L. Cevenini, E. Michelini, and B. R. Branchini, "A portable bioluminescence engineered cell-based biosensor for on-site applications," Biosensors \& Bioelectronics, vol. 26, no. 8, pp. 3647-3653, 2011.

[54] D. O. Fesenko, T. V. Nasedkina, D. V. Prokopenko, and A. D. Mirzabekov, "Biosensing and monitoring of cell populations using the hydrogel bacterial microchip," Biosensors \& Bioelectronics, vol. 20, no. 9, pp. 1860-1865, 2005.

[55] M. Held, W. Schuhmann, K. Jahreis, and H.-L. Schmidt, "Microbial biosensor array with transport mutants of Escherichia coli $\mathrm{K} 12$ for the simultaneous determination of mono-and disaccharides," Biosensors and Bioelectronics, vol. 17, no. 11-12, pp. 1089-1094, 2002.

[56] R. Pedahzur, R. Rosen, and S. Belkin, "Stabilization of recombinant bioluminescent bacteria for biosensor applications," Cell Preservation Technology, vol. 2, no. 4, pp. 260-269, 2004.

[57] B. Kempf and E. Bremer, "Uptake and synthesis of compatible solutes as microbial stress responses to high-osmolality environments," Archives of Microbiology, vol. 170, no. 5, pp. 319-330, 1998.

[58] A. Kuppardt, A. Chatzinotas, U. Breuer, J. R. van der Meer, and H. Harms, "Optimization of preservation conditions of As (III) bioreporter bacteria," Applied Microbiology and Biotechnology, vol. 82, no. 4, pp. 785-792, 2009.

[59] A. Date, P. Pasini, and S. Daunert, "Fluorescent and bioluminescent cell-based sensors: strategies for their preservation," 
in Whole Cell Sensing Systems I, vol. 117 of Advances in Biochemical Engineering/Biotechnology, pp. 57-75, Springer, Berlin, Germany, 2010.

[60] I. Biran, D. M. Rissin, E. Z. Ron, and D. R. Walt, "Optical imaging fiber-based live bacterial cell array biosensor," Analytical Biochemistry, vol. 315, no. 1, pp. 106-113, 2003.

[61] T. Charrier, C. Chapeau, L. Bendria, P. Picart, P. Daniel, and G. Thouand, "A multi-channel bioluminescent bacterial biosensor for the on-line detection of metals and toxicity. Part II: technical development and proof of concept of the biosensor," Analytical and Bioanalytical Chemistry, vol. 400, no. 4, pp. 1061-1070, 2011.

[62] N. Gou, A. Onnis-Hayden, and A. Z. Gu, "Mechanistic toxicity assessment of nanomaterials by whole-cell-array stress genes expression analysis," Environmental Science \& Technology, vol. 44, no. 15, pp. 5964-5970, 2010.

[63] J.-M. Ahn, J. H. Kim, J. H. Kim, and M. B. Gu, "Randomly distributed arrays of optically coded functional microbeads for toxicity screening and monitoring," Lab on a Chip, vol. 10, no. 20, pp. 2695-2701, 2010.

[64] X. Zhang, S. Wiseman, H. Yu, H. Liu, J. P. Giesy, and M. Hecker, "Assessing the toxicity of naphthenic acids using a microbial genome wide live cell reporter array system," Environmental Science and Technology, vol. 45, no. 5, pp. 1984-1991, 2011.

[65] M.-A. Woo, M. I. Kim, B. J. Yu et al., "Cell-based quantification of homocysteine utilizing bioluminescent Escherichia coli auxotrophs," Analytical Chemistry, vol. 83, no. 8, pp. 3089-3095, 2011.

[66] M.-A. Woo, M. I. Kim, D. Cho, and H. G. Park, "Cell-based galactosemia diagnosis system based on a galactose assay using a bioluminescent Escherichia coli array," Analytical Chemistry, vol. 85, no. 22, pp. 11083-11089, 2013.

[67] C. Barsalobres-Cavallari, V. De Rosa, F. Nogueira et al., "A novel system for large-scale gene expression analysis: bacterial colonies array," Applied Microbiology and Biotechnology, vol. 71, no. 6, pp. 963-969, 2006.

[68] L. R. Mesak, S. Qi, I. Villanueva, V. Miao, and J. Davies, "Staphylococcus aureus promoter-lux reporters for drug discovery," Journal of Antibiotics, vol. 63, no. 8, pp. 492-498, 2010.

[69] T. Elad, H. B. Seo, S. Belkin, and M. B. Gu, "High-throughput prescreening of pharmaceuticals using a genome-wide bacterial bioreporter array," Biosensors \& Bioelectronics, vol. 68, pp. 699704, 2015. 

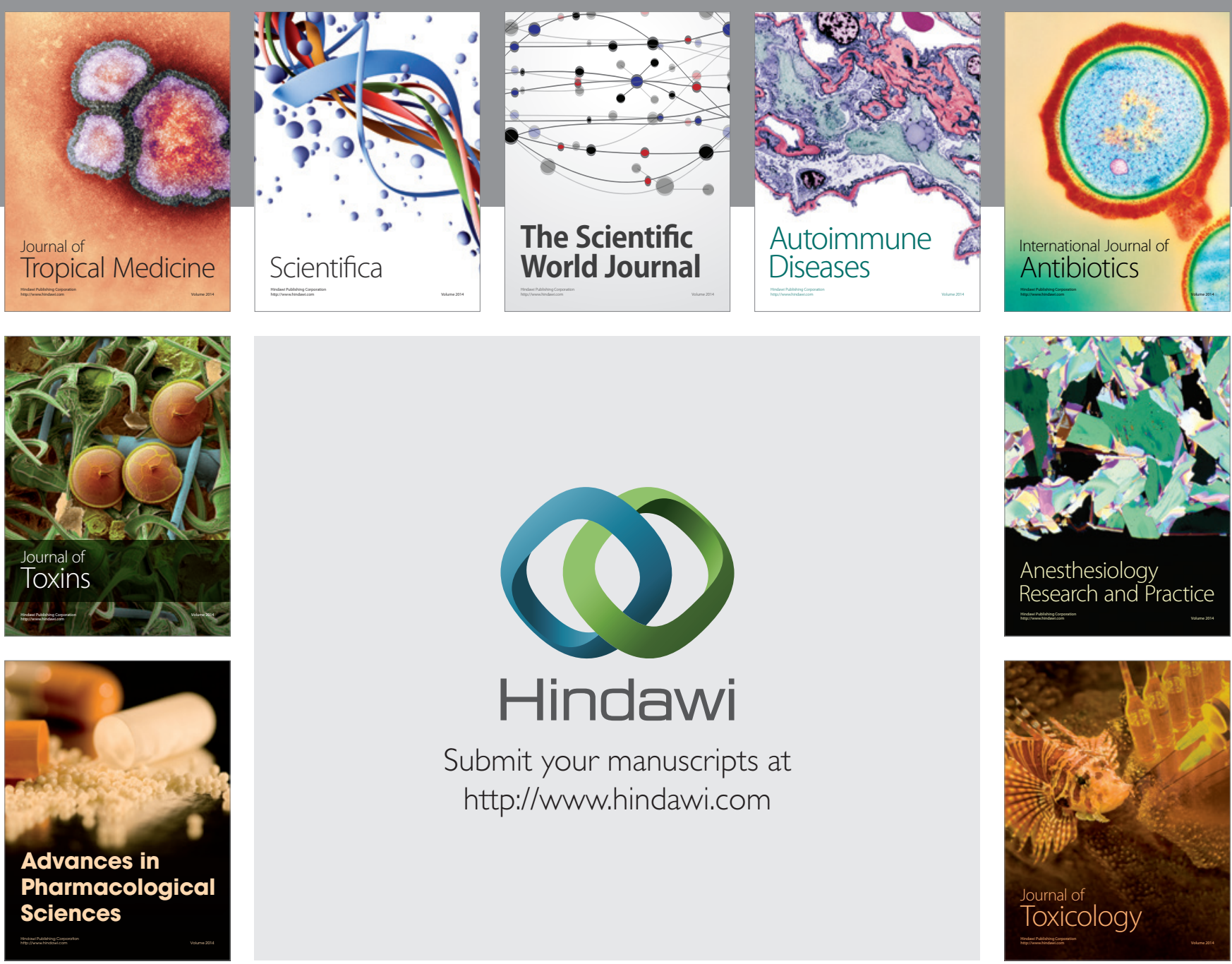

\section{Hindawi}

Submit your manuscripts at

http://www.hindawi.com
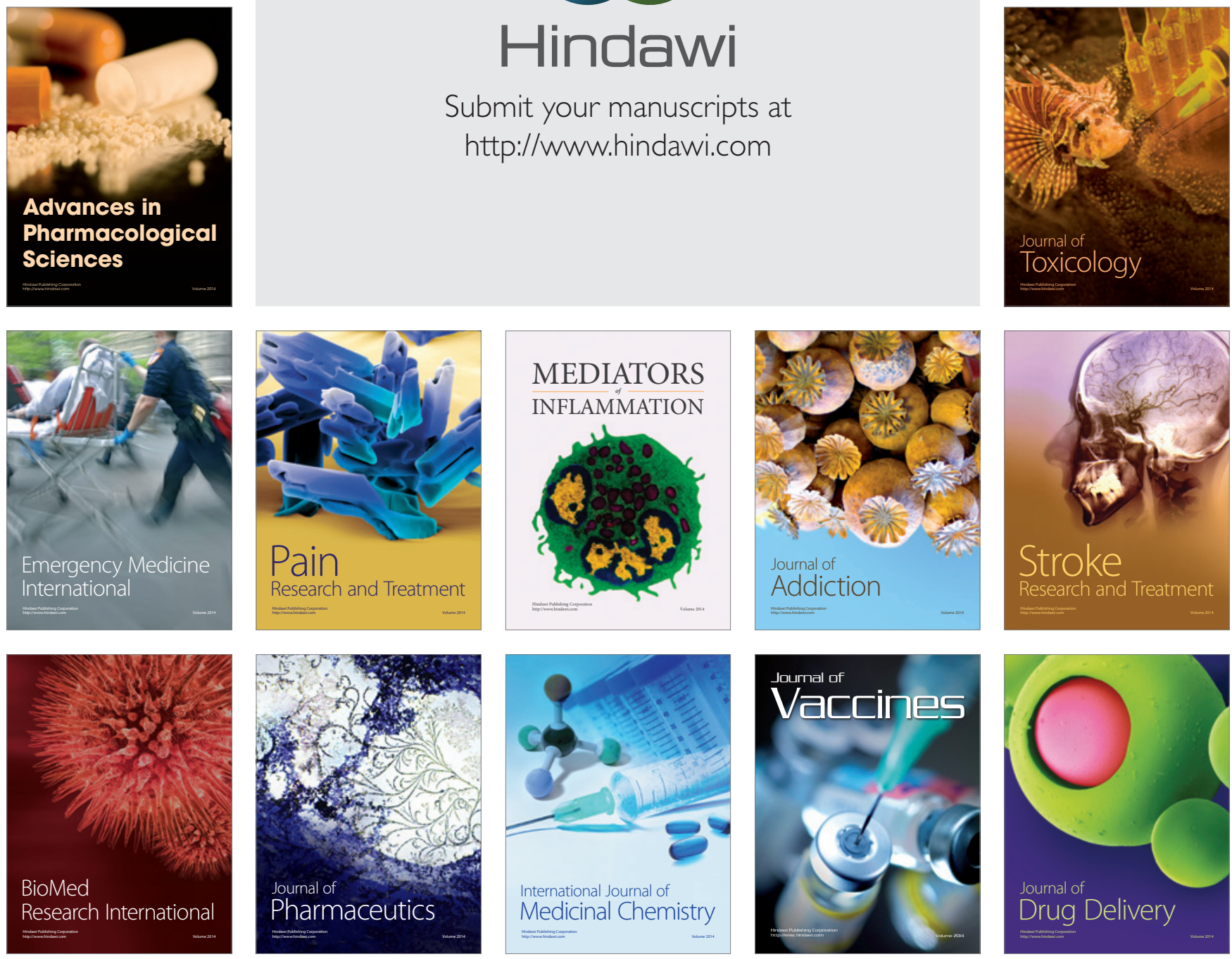